\title{
AVALIAÇÃO DAS CONDUTAS ADOTADAS POR PROFISSIONAIS NA UTILIZAÇÃO DE COROAS METALO-CERÂMICAS
}

\author{
ASSESSMENT OF CLINICAL PROCEEDINGS ADOPTED BY DENTAL \\ PROFESSIONALS REGARDING THE EMPLOYMENT OF CERAMIC FUSED TO \\ METAL CROWNS
}

\author{
Carlos Neanes SANTOS \\ Mestre e Doutor em Reabilitação Oral na Faculdade de Odontologia de Bauru - Universidade de São Paulo. \\ Melissa Thiemi KATO \\ Cirurgiã-dentista pela Faculdade de Odontologia de Bauru, Universidade de São Paulo. \\ Paulo César Rodrigues CONTI \\ Professor Doutor do Departamento de Prótese da Faculdade de Odontologia de Bauru - Universidade de São Paulo.
}

\begin{abstract}
$\bar{A}$ fim de avaliar a opinião da classe odontológica sobre a utilização das coroas metalo-cerâmicas na prática odontológica, aplicou-se um questionário de 20 questões a cirurgiões-dentistas da cidade de Aracaju - SE, e a cirurgiões-dentistas e estudantes de pós-graduação em odontologia, na área de prótese dental, da cidade de BauruSP. Concluiu-se que: 1. As coroas metalo-cerâmicas são o tipo de restauração protética mais empregado em Odontologia. 2. A maioria dos dentistas refere-se às coroas metalo-cerâmicas como restaurações bem sucedidas, indicando superfícies oclusais metálicas para a maioria dos pacientes. 3. Apesar da maior parte dos profissionais utilizar as ligas de níquel-cromo nas coroas metalo-cerâmicas de seus pacientes, os mesmos prefeririam que ligas nobres ou semi-nobres fossem empregadas em suas próprias restaurações. 4. A maioria dos entrevistados emprega as coroas metalo-cerâmicas na restauração de dentes anteriores $(57,23 \%)$. Entretanto, esse valor se deve à preferência dos dentistas de Aracaju (78\%) por esse tipo de restauração, ao passo que, em Bauru, prevaleceu o número de respostas favoráveis às coroas de porcelana pura. 5. O cimento de fosfato de zinco foi o cimento de escolha da maioria dos profissionais. 6 . A preferência da maior parte dos entrevistados, com relação à porcelana utilizada foi pela porcelana Vita $(34,34 \%)$, em comparação às porcelanas Noritake e Dulceram Plus $(13,86 \%)$. 6. Ficou evidente o desejo dos entrevistados quanto ao desenvolvimento de mecanismos que facilitem o reparo das coroas metalocerâmicas.
\end{abstract}

UNITERMOS: Questionários; Prótese parcial fixa; Porcelana dentária.

\section{INTRODUÇÃO}

A utilização das coroas protéticas metalo-cerâmicas (MC) na prática odontológica apresentou acentuado crescimento nos últimos 50 anos. Atualmente, trata-se de um dos tipos de restauração protética mais utilizada em Odontologia Restauradora ${ }^{1}$. Segundo Seymour et al. ${ }^{22}$ o serviço dental geral da Inglaterra registrou até 31 de março de 1997 a entrada de 1.322 .731 unidades na Inglaterra, isso corresponde à confecção de $95 \%$ das restaurações prescritas para os adulto, sem contar a estatística dos consultórios particulares. Introduzido na década de 50, o sistema metalocerâmico trouxe significativas mudanças na execução das restaurações protéticas ${ }^{10,16}$. Esse sistema alia as propriedades de resistência da estrutura metálica à excelente estética da cerâmica, possibilitando a restauração de elementos dentais de maneira altamente satisfatória. ${ }^{5,7,18}$

Apesar do grau de aprimoramento das ligas metálicas e das cerâmicas, a longevidade dos trabalhos protéticos ainda é motivo de grande preocupação tanto por parte do cirurgiãodentista quanto do paciente. ${ }^{21} \mathrm{~A}$ longevidade da restauração MC encontra-se vinculada a uma série de fatores tais como: correto planejamento da infra-estrutura metálica; qualidade da liga metálica utilizada; compatibilidade entre a cerâmica e a liga metálica escolhida; integridade estrutural e estado biológico dos dentes pilares e tecidos periodontais; grau de 
carga funcional e/ou parafuncional exercida sobre as restaurações; manutenção apropriada; controle de placa realizado pelo paciente, bem como a precisão com a qual o técnico e o profissional trabalham em todos os passos de sua confecção. ${ }^{19} \mathrm{O}$ prognóstico satisfatório de dentes reabilitados proteticamente está na dependência direta do controle e manutenção desses fatores. Esses aspectos exigem do cirurgião-dentista controle sobre ambos, o paciente e o técnico em prótese dentária. Entretanto, a responsabilidade sobre o trabalho executado sempre recai sobre o cirurgiãodentista, e é a este que o paciente irá reclamar eventuais reparos.

Além disso, o conhecimento das causas que levam ao fracasso das próteses fixas ajudaria os cirurgiões-dentistas a dispor de meios mais eficazes de tratamento e a prognosticar com maior segurança. O cirurgião-dentista deve ainda estar ciente da longevidade média dos vários tipos de próteses e dos materiais mais indicados para a construção e cimentação dos mesmos. ${ }^{25}$

O objetivo desta pesquisa foi avaliar a conduta diária dos cirurgiões-dentistas com relação às restaurações MC, por meio de um questionário, o qual relacionou aspectos relativos ao seu emprego, técnica de confecção, tipo de liga, reavaliações periódicas e prognóstico das mesmas.

\section{MATERIAL E MÉTODO}

A pesquisa constituiu de um questionário composto por vinte perguntas de múltipla escolha. Esse questionário foi formulado a partir de uma pesquisa desenvolvida pelo Comitê de Investigação Científica da Academia Americana de Odontologia Estética, inserindo-se algumas modificações devido ao desenvolvimento de novos materiais restauradores. Responderam ao questionário: 50 cirurgiõesdentistas que realizam trabalhos protéticos rotineiramente em seus consultórios, independentemente de serem especialistas, na cidade de Aracaju-SE; 67 cirurgiõesdentistas da cidade de Bauru-SP e 49 estudantes de especialização, mestrado ou doutorado, na área de Prótese ou Reabilitação Oral, da Faculdade de Odontologia de Bauru, da Universidade de São Paulo. O nome de cada entrevistado foi omitido para totalização dos resultados. Apenas um entrevistador coletou e inseriu os dados num programa para análise estatística (Statistica for Windows v.5.0). Todos os resultados foram colocados em valores percentuais ao lado de cada resposta às 20 perguntas formuladas, obedecendo à seguinte ordem: 1 odos os indivíduos entrevistados; $2^{\circ}$ profissionais residentes em Aracaju; $3^{\circ}$ profissionais residentes em Bauru e $4^{\circ}$ alunos dos cursos de pós-graduação da Faculdade de Odontologia de Bauru (especialização, mestrado ou doutorado em Prótese Dental/Reabilitação Oral).

\section{RESULTADOS E DISCUSSÃO}

Os resultados estão listados em tabelas. Cada tabela corresponde a uma pergunta do questionário e os percentuais de respostas encontram-se nas colunas para cada categoria de profissionais e para a amostra como um todo.

A maioria dos dentistas americanos ${ }^{2}$ e europeus ${ }^{22}$ utilizam a prótese MC para a substituição das unidades dentárias posteriores ${ }^{2}$ o que concorda, de maneira geral com a presente pesquisa (Tabela 1), muitos profissionais, principalmente em Aracaju, ainda preferem o uso de outros tipos de restaurações. Não se pode afirmar que essa discrepância se deva a diferenças no poder aquisitivo das populações de Aracaju e Bauru, pois os valores médios do salário de ambas as populações são similares ${ }^{6}$. Apesar de a presente pesquisa não informar que outros tipos de restaurações são utilizados pelos profissionais de Aracaju, pode-se inferir que as coroas metaloplásticas ou totais metálicas sejam os tipos utilizados em opção às $\mathrm{MC}$, não sendo possível deduzir, com base nas informações disponíveis, as razões para o equilíbrio entre a utilização ora na maioria ora em alguns pacientes.

A preferência dos profissionais de Aracaju pela restauração $\mathrm{MC}$ dos dentes anteriores pode ser explicada pela menor difusão dos resultados satisfatórios das restaurações de cerâmica pura (In-Ceram, IPS Empress II e Procera) nessa região, em comparação à região sudeste, principalmente São Paulo, onde geralmente se inicia a divulgação dos novos materiais na área odontológica e onde se concentram as melhores faculdades de odontologia do Brasil, nas quais são testados muitos dos materiais lançados no mercado (Tabela 2). Verificou-se que mais dentistas em Bauru usam coroas de porcelana pura na região anterior e

TABELA 1- Quando há necessidade de restabelecer a perda das unidades dentárias posteriores, com que freqüência você utiliza a coroa metalo-cerâmica?

\begin{tabular}{|c|c|c|c|c|}
\hline & Aracaju & Profissionais/Bauru & Estudantes/Bauru & Total \\
\hline Sempre & $4 \%$ & $11,94 \%$ & $12,25 \%$ & $9,64 \%$ \\
\hline Maioria dos pacientes & $40 \%$ & $62,69 \%$ & $67,35 \%$ & $57,23 \%$ \\
\hline $50 \%$ dos pacientes & $14 \%$ & $7,46 \%$ & $10,20 \%$ & $10,24 \%$ \\
\hline Alguns pacientes & $42 \%$ & $17,91 \%$ & $10,20 \%$ & $22,89 \%$ \\
\hline Nunca & $0 \%$ & $0 \%$ & $0 \%$ & $0 \%$ \\
\hline Total & $100 \%$ & $100 \%$ & $100 \%$ & $100 \%$ \\
\hline
\end{tabular}


mais coroas MC na região posterior (Tabela 3) do que em Aracaju. Apesar da compatibilidade econômica entre as duas cidades, talvez diferenças culturais quanto ao apelo dos pacientes pela estética exerça algum papel nesse comportamento diferenciado.

A maioria dos cirurgiões-dentistas $(61,44 \%)$ utiliza ligas de níquel-cromo (Ni-Cr) para a confecção de coroas MC, seguidas pelas ligas seminobres $(12,65 \%)$ e pelo ouro (4,22\%). Entretanto, um número significativo $(19,88 \%)$ deixa a escolha a critério do laboratório. No estudo de Christensen $^{2}, 64 \%$ dos entrevistados preferiram o uso de ligas com algum conteúdo de ouro (alto ou baixo). Para Pegoraro, ${ }^{17}$ é inquestionável a superioridade das ligas nobres em relação às ligas de níquel-cromo, entretanto, ao se analisarem as vantagens e desvantagens das ligas de $\mathrm{Ni}-\mathrm{Cr}$, chega-se à conclusão de que a relação custo/benefício dessas últimas é muito positiva. $\mathrm{O}$ autor acrescenta que, ao se considerar apenas o aspecto econômico, as ligas nobres têm um peso importante no orçamento das classes econômicas com menor poder aquisitivo e este pode ser o fator de aceitação ou recusa do tratamento por parte do paciente.

Dos cirurgiões-dentistas, 78,32\% $(28,92 \%+49,40 \%)$ utilizam porcelana nas superfícies oclusais dos dentes posteriores, sempre ou na maior parte dos pacientes, coincidindo com os achados de Christensen ${ }^{2}$, em que $78 \%$ dos entrevistados responderam que também preferem a porcelana na superfície oclusal. Esses dados confirmam um uso surpreendentemente alto da porcelana nas superfícies oclusais. Apesar da grande discussão referente ao desgaste dos dentes naturais pela porcelana ${ }^{4}$, a estética assumiu maior importância em comparação à aceitabilidade funcional (Tabela 4).

O exame periódico a cada ano é o mais realizado pelos cirurgiões-dentistas $(42,17 \%)$ para a avaliação de sucesso ou insucesso após a colocação de próteses, sendo que $13,25 \%$ não realizam nenhum controle. Segundo Lindhe ${ }^{12}$, o intervalo máximo inter-avaliações de controle deveria ser de 6 meses, principalmente em próteses extensas, devido à dificuldade de higienização que as mesmas oferecem (Tabela 5).

As avaliações de controle das próteses instaladas são realizadas, em sua maioria, pelo profissional que a confeccionou $(92,17 \%)$ enquanto que apenas $0,6 \%$ das avaliações de controle é delegado a outro clínico (Tabela 6). Nota-se uma grande preocupação do cirurgião-dentista em fazer o controle periódico, pois nem todo paciente, por mais instruído que seja com relação a higienização de sua prótese, consegue realizá-la corretamente. Assim, a motivação continuada dos pacientes por parte do CD é de fundamental importância para o aumento da longevidade dos $\operatorname{casos}^{12}$.

Embora 62,05\% dos profissionais façam a seleção da cor da cerâmica, um número significativo $(37,35 \%)$ prefere fazê-la juntamente com o protético (Tabela 7). Isto denota a falta de segurança que o dentista possui no momento da escolha da cor, mostrando uma formação inadequada. Muitas

TABELA 2- E nos dentes anteriores, qual o tipo de coroa que você está atualmente utilizando?

\begin{tabular}{|c|c|c|c|c|}
\hline & Aracaju & Profissionais/Bauru & Estudantes/Bauru & Total \\
\hline Metalo-cerâmica & $78 \%$ & $58,21 \%$ & $34,69 \%$ & $57,23 \%$ \\
\hline Cerâmica pura & $6 \%$ & $37,31 \%$ & $51,02 \%$ & $31,93 \%$ \\
\hline Resina composta indireta & $16 \%$ & $2,99 \%$ & $0 \%$ & $6,02 \%$ \\
\hline Colar-less & $0 \%$ & $1,49 \%$ & $14,29 \%$ & $4,82 \%$ \\
\hline Outros & $0 \%$ & $0 \%$ & $0 \%$ & $0 \%$ \\
\hline Total & $100 \%$ & $100 \%$ & $100 \%$ & $100 \%$ \\
\hline
\end{tabular}

TABELA 3- Ao confeccionar a coroa metalo-cerâmica, você utiliza que tipo de liga?

\begin{tabular}{llccc}
\hline & Aracaju & Profissionais/Bauru & Estudantes/Bauru & Total \\
\hline Ligas nobres de ouro & & & & \\
cerâmico & $0 \%$ & $1,49 \%$ & $12,25 \%$ & $4,22 \%$ \\
Ligas seminobres & $8 \%$ & $8,96 \%$ & $22,45 \%$ & $12,65 \%$ \\
Ligas de níquel-cromo & $58 \%$ & $65,67 \%$ & $59,18 \%$ & $61,44 \%$ \\
Outros & $4 \%$ & $0 \%$ & $2,04 \%$ & $1,81 \%$ \\
Deixa a escolha a critério & & & $4,08 \%$ & $19,88 \%$ \\
do laboratório & $30 \%$ & $23,88 \%$ & $100 \%$ & $100 \%$ \\
Total & $100 \%$ & $100 \%$ & & \\
\hline
\end{tabular}


faculdades no Brasil não possuem uma disciplina de estética tampouco ensinam de maneira consistente os passos para seleção de cor. Isso fica delegado ao técnico que, muitas vezes o faz de maneira não individualizada.

Dos cirurgiões-dentistas, $79,52 \%$ recebem a infraestrutura da prótese seccionada para execução posterior da solda, apesar de $32 \%$ dos profissionais de Aracaju receberem suas peças em monobloco, não realizando o procedimento de soldagem. Pegoraro ${ }^{17}$ explicou a importância de se realizar a soldagem da infra-estrutura, por esta possibilitar um melhor ajuste das peças aos respectivos pilares (Tabela
8). A técnica mais comumente empregada para moldagem de preparos é a técnica do casquete, cujo arrasto leva ao deslocamento dos mesmos. Poucos profissionais no Brasil utilizam fio retrator sem o uso de casquetes, com técnica única ou dupla moldagem ${ }^{23}$, o que dispensaria o procedimento de soldagem.

Fornecer ao técnico o máximo de informações que auxiliem na reprodução das características dentais é de suma importância para a obtenção do sucesso clínico das restaurações anteriores. A maioria dos profissionais $(86,75 \%)$ utiliza esse procedimento, embora $24 \%$ do

TABELA 4- Quando você utiliza coroas metalo-cerâmicas, qual a porcentagem do uso de superfícies oclusais em porcelana?

\begin{tabular}{lcccc}
\hline & Aracaju & Profissionais/Bauru & Estudantes/Bauru & Total \\
\hline $\begin{array}{l}\text { Sempre } \\
\text { Na maior parte dos }\end{array}$ & $42 \%$ & $14,93 \%$ & $34,69 \%$ & $28,92 \%$ \\
pacientes & $32 \%$ & & & \\
Em aproximadamente & & $61,19 \%$ & $51,02 \%$ & $49,40 \%$ \\
$50 \%$ dos pacientes & $6 \%$ & & & \\
Em alguns pacientes & $18 \%$ & $4,48 \%$ & $2,04 \%$ & $12,25 \%$ \\
Nunca & $2 \%$ & $16,42 \%$ & $0 \%$ & $15,66 \%$ \\
Não responderam & $2 \%$ & $1,49 \%$ & $0,6 \%$ & $1,2 \%$ \\
Total & $100 \%$ & $1,49 \%$ & $100 \%$ & $100 \%$ \\
\hline
\end{tabular}

TABELA 5- Você tem algum controle sobre o sucesso ou insucesso após a instalação de suas próteses?

\begin{tabular}{|c|c|c|c|c|}
\hline & Aracaju & Profissionais/Bauru & Estudantes/Bauru & Total \\
\hline \multicolumn{5}{|l|}{ Exame periódico de } \\
\hline 6 em 6 meses & $36 \%$ & $35,82 \%$ & $48,98 \%$ & $39,76 \%$ \\
\hline \multicolumn{5}{|l|}{ Exame periódico } \\
\hline a cada 1 ano & $38 \%$ & $49,25 \%$ & $36,74 \%$ & $42,17 \%$ \\
\hline \multicolumn{5}{|l|}{ Exame periódico de } \\
\hline 3 em 3 meses & $2 \%$ & $4,48 \%$ & $8,16 \%$ & $4,82 \%$ \\
\hline Não tenho controle & $24 \%$ & $10,45 \%$ & $6,12 \%$ & $13,25 \%$ \\
\hline Total & $100 \%$ & $100 \%$ & $100 \%$ & $100 \%$ \\
\hline
\end{tabular}

TABELA 6- Em relação ao controle de seus pacientes e manutenção da prótese instalada

\begin{tabular}{|c|c|c|c|c|}
\hline & Aracaju & Profissionais/Bauru & Estudantes/Bauru & Total \\
\hline \multicolumn{5}{|l|}{ Você delega esta função } \\
\hline a outro clínico & $0 \%$ & $0 \%$ & $2,04 \%$ & $0,6 \%$ \\
\hline \multicolumn{5}{|l|}{ Executa este controle em } \\
\hline seu próprio consultório & $88 \%$ & $97,01 \%$ & $89,80 \%$ & $92,17 \%$ \\
\hline Nenhuma das respostas & $12 \%$ & $2,99 \%$ & $8,16 \%$ & $7,23 \%$ \\
\hline Total & $100 \%$ & $100 \%$ & $100 \%$ & $100 \%$ \\
\hline
\end{tabular}


profissionais de Aracaju não o façam (Tabela 9). Esses dados refletem como a adoção de procedimentos visando a uma melhor estética dos casos é heterogênea nas duas regiões, podendo, mais uma vez, refletir as diferenças quanto a formação acadêmica desses profissionais.

A opção pela realização da caracterização extrínseca antes do glazeamento mostrou-se bem equilibrada, sendo que 58\% dos profissionais de Aracaju não a realizam (Tabela 10). Vê-se que a utilização da caracterização extrínseca é um recurso de caracterização menos difundido do que o envio de informações ao técnico sobre caracterização intrínseca (Tabela 9).

Dentre os cirurgiões-dentistas, 35,53\% não sabem que tipo de cerâmica é utilizada para a confecção de suas coroas MC. Dentre os tipos de cerâmicas citadas, a mais utilizada foi a Vita $(34,34 \%)$, seguida, em igual proporção, pela
Noritake e pela Dulceram Plus, com 13,86\% cada. Com relação ao trabalho de Christensen ${ }^{2}$, houve uma aceitação de $56 \%$ pela porcelana Vita e $18 \%$ para Ceramco (Tabela 11). A natureza das propriedades químicas e físicas de cada cerâmica acaba sendo colocada em segundo plano, onde vale mais a penetração que o produto tem no mercado.

Apesar de 66,26\% dos cirurgiões-dentistas preferirem a coroa $\mathrm{MC}$, Christensen ${ }^{1}$ encontrou resultados contraditórios, onde os americanos preferiram o uso de oclusais metálicas em suas próprias restaurações apesar de usarem oclusais de cerâmica em seus pacientes (Tabela 12). Sabe-se que apesar da evolução dos sistemas de cerâmica pura, o número de falhas mecânicas em coroas confeccionadas com esse sistema ainda é superior ao das coroas MC e estudos longitudinais sobre os novos materiais cerâmicos apontam para sua utilização apenas na região anterior ${ }^{15}$. Assim, para

TABELA 7- Quem faz a seleção da cor da cerâmica?

\begin{tabular}{|c|c|c|c|c|}
\hline & Aracaju & Profissionais/Bauru & Estudantes/Bauru & Total \\
\hline Cirurgião-dentista & $68 \%$ & $56,72 \%$ & $63,27 \%$ & $62,05 \%$ \\
\hline Técnico & $0 \%$ & $1,49 \%$ & $0 \%$ & $0,6 \%$ \\
\hline \multicolumn{5}{|l|}{ ambos, em comum } \\
\hline acordo & $32 \%$ & $41,79 \%$ & $36,73 \%$ & $37,35 \%$ \\
\hline Total & $100 \%$ & $100 \%$ & $100 \%$ & $100 \%$ \\
\hline
\end{tabular}

TABELA 8- Como você recebe do seu técnico uma prótese de 3 elementos para prova de infra-estrutura?

\begin{tabular}{lcccc}
\hline & Aracaju & Profissionais/Bauru & Estudantes/Bauru & Total \\
\hline Monobloco & $32 \%$ & $14,93 \%$ & $16,33 \%$ & $20,48 \%$ \\
Em duas partes & $68 \%$ & $85,07 \%$ & $83,67 \%$ & $79,52 \%$ \\
Total & $100 \%$ & $100 \%$ & $100 \%$ & $100 \%$ \\
\hline
\end{tabular}

TABELA 9- Você informa ao técnico, detalhes de caracterização intrínseca de sua prótese?

\begin{tabular}{lcccc}
\hline & Aracaju & Profissionais/Bauru & Estudantes/Bauru & Total \\
\hline Sim & $76 \%$ & $95,52 \%$ & $85,71 \%$ & $86,75 \%$ \\
Não & $24 \%$ & $4,48 \%$ & $14,29 \%$ & $13,25 \%$ \\
Total & $100 \%$ & $100 \%$ & $100 \%$ & $100 \%$ \\
\hline
\end{tabular}

TABELA 10- Você realiza caracterização extrínseca (corantes) antes do glazeamento final?

\begin{tabular}{lcccc}
\hline & Aracaju & Profissionais/Bauru & Estudantes/Bauru & Total \\
\hline Sim & $42 \%$ & $58,21 \%$ & $53,06 \%$ & $51,81 \%$ \\
Não & $58 \%$ & $41,79 \%$ & $46,94 \%$ & 48,19 \\
Total & $100 \%$ & $100 \%$ & $100 \%$ & $100 \%$ \\
\hline
\end{tabular}


restaurações posteriores, devido à magnitude das forças que atuam nessa região, a preferência do clínico acaba recaindo sobre as coroas MC.

Embora a indicação da liga para a confecção de coroas MC seja preferencialmente a de Ni-Cr para seus pacientes (Tabela 3), a maioria dos entrevistados preferiu o emprego de ligas nobres em restaurações confeccionadas em seus próprios dentes posteriores $(42,77 \%)$, deixando as ligas de Ni-Cr como segunda opção (Tabela 13).

Devido às respostas contraditórias em relação a mesma pergunta realizada em questões anteriores, concluiu-se que os profissionais preferem, naturalmente, as ligas nobres, por estas apresentarem melhor adaptação ${ }^{11}$, mas indicam o uso das de Ni-Cr em seus pacientes por razões puramente econômicas. Deve-se salientar que, desde que o profissional conheça a utilização, os diferentes cuidados, vantagens e desvantagens de cada uma das ligas e que seja dada ao paciente a possibilidade de escolha, não há problema quanto à utilização das ligas básicas.

Tradicionalmente, o cimento de fosfato de zinco tem sido o agente cimentante mais utilizado, a despeito de suas desvantagens bem documentadas ${ }^{10}$, particularmente sua acidez e alta solubilidade, o que aumenta o risco de infiltração marginal ${ }^{17}$. Apesar desses problemas, esse cimento continua sendo amplamente empregado na clínica odontológica, devido a sua facilidade técnica e sucesso

TABELA 11- Qual o tipo de cerâmica que você usa em suas coroas metalo-cerâmicas?

\begin{tabular}{|c|c|c|c|c|}
\hline & Aracaju & Profissionais/Bauru & Estudantes/Bauru & Total \\
\hline Biobond & $0 \%$ & $1,49 \%$ & $0 \%$ & $0,6 \%$ \\
\hline Ceramco & $0 \%$ & $1,49 \%$ & $2,04 \%$ & $1,21 \%$ \\
\hline Shofu & $0 \%$ & $0 \%$ & $0 \%$ & $0 \%$ \\
\hline Vita & $34 \%$ & $31,35 \%$ & $38,77 \%$ & $34,34 \%$ \\
\hline Noritake & $4 \%$ & $16,42 \%$ & $20,41 \%$ & $13,86 \%$ \\
\hline Willceram & $0 \%$ & $0 \%$ & $2,04 \%$ & $0,6 \%$ \\
\hline Dulceram plus & $6 \%$ & $19,40 \%$ & $14,29 \%$ & $13,86 \%$ \\
\hline Não sei & $56 \%$ & $29,85 \%$ & $22,45 \%$ & $35,53 \%$ \\
\hline Total & $100 \%$ & $100 \%$ & $100 \%$ & $100 \%$ \\
\hline
\end{tabular}

TABELA 12- Se seu próprio molar precisasse de uma restauração protética, que tipo de coroa você usaria:

\begin{tabular}{lcccc}
\hline & Aracaju & Profissionais/Bauru & Estudantes/Bauru & Total \\
\hline Resina & $8 \%$ & $1,49 \%$ & $4,08 \%$ & $4,22 \%$ \\
Metalo-cerâmica & $66 \%$ & $65,67 \%$ & $67,35 \%$ & $66,26 \%$ \\
Cerâmica pura & $24 \%$ & $26,87 \%$ & $22,45 \%$ & $24,7 \%$ \\
Total metálica em ouro & $2 \%$ & $4,48 \%$ & $6,12 \%$ & $4,22 \%$ \\
Total metálica em & & & & $0,6 \%$ \\
níquel-cromo & $0 \%$ & $1,49 \%$ & $100 \%$ & $100 \%$ \\
Total & $100 \%$ & $100 \%$ & & \\
\hline
\end{tabular}

TABELA 13- Se seus dentes posteriores necessitassem de uma prótese fixa, que tipo de liga você usaria em sua metalocerâmica

\begin{tabular}{lcccc}
\hline & Aracaju & Profissionais/Bauru & Estudantes/Bauru & Total \\
\hline Ligas nobres & $30 \%$ & $35,82 \%$ & $65,30 \%$ & $42,77 \%$ \\
Ligas seminobres & $24 \%$ & $19,40 \%$ & $16,33 \%$ & $19,88 \%$ \\
Ligas níquel-cromo & $26 \%$ & $35,82 \%$ & $16,33 \%$ & $27,11 \%$ \\
A critério do laboratório & $20 \%$ & $8,96 \%$ & $2,04 \%$ & $10,24 \%$ \\
Total & $100 \%$ & $100 \%$ & $100 \%$ & $100 \%$ \\
\hline
\end{tabular}


clínico $^{20}$, fato confirmado na presente pesquisa. Com a introdução de materiais alternativos, os cimentos resinosos tornaram-se populares, primariamente devido a sua insolubilidade e adesão à estrutura dental. A principal indicação dos cimentos resinosos é a cimentação de coroas de cerâmica pura. Sua capacidade de união à estrutura dentária confere a esse tipo de restauração maior resistência por agir como férula interna. Entretanto, sua maior viscosidade muitas vezes dificulta o correto assentamento da restauração, podendo levar a maiores desajustes marginais além de interferências oclusais ${ }^{20}$, principalmente em restaurações totais. Interessante notar que, apesar de pouco utilizado para a cimentação de coroas MC, 10,20\% dos estudantes entrevistados da Faculdade de Odontologia de Bauru utilizam-no com essa finalidade, a despeito de essa não ser a medida preconizada por essa instituição. Com o advento dos cimentos resinosos de presa dual, os mesmos passaram a ter indicação também para a cimentação de coroas com infra-estrutura metálica, como é o caso das coroas MC. Tornando a necessidade do controle de umidade durante sua manipulação, sua principal desvantagem. Sabese que, em se tratando de coroas totais, essas condições de isolamento, muitas vezes não são possíveis de serem obtidas, podendo comprometer a qualidade da cimentação e, conseqüentemente, predispor a interface à infiltração marginal. A popularidade dos cimentos de ionômero de vidro deve-se à liberação de flúor bem como a sua capacidade de adesão ao esmalte e à dentina. Além disso, com a inclusão de componentes resinosos ao ionômero de vidro, esse material parece exibir desempenho semelhante aos cimentos resinosos quanto à solubilidade, microinfiltração, restando como desvantagem o risco de sorção de água se exposto à umidade precoce ${ }^{20}$. Os estudos apontam para o cimento de ionômero de vidro modificado por resina como aquele mais promissor quanto à união das melhores características e compensação das desvantagens dos demais (como a alta solubilidade do fosfato de zinco e a necessidade absoluta de ausência de umidade dos cimentos resinosos).

Entretanto, na presente pesquisa, verifica-se que o cimento de ionômero de vidro foi menos utilizado do que os cimentos de fosfato de zinco e resinosos duais (Tabela 14). O pouco tempo de utilização dos cimentos de ionômero de vidro ainda podem levar à certa falta de segurança por parte dos clínico em utilizá-lo. Merecem atenção os altos índices de uso do cimento resinoso dual em Aracaju para a cimentação de coroas MC quanto aos cuidados em relação ao controle de umidade e à ocorrência de desajustes póscimentação. Essa última característica não apenas aumenta a espessura da linha de cimentação como também leva à necessidade de ajustes na porcelana que não poderão ser glazeados. A presença de áreas na superfície da porcelana sem o devido polimento pode levar ao desgaste mais acentuado da dentição antagonista e comprometer a resistência do material ${ }^{13}$.

Resultados similares foram obtidos por Christensen ${ }^{2}$, em que $70 \%$ dos entrevistados responderam que durante os últimos 10 anos as restaurações com coroas MC foram muito bem sucedidas. Esses resultados, aliados aos de outros trabalhos ${ }^{8,9,24,25}$, permitem-nos declarar que, em relação ao tempo, parece razoável afirmar que uma expectativa de 10 anos ou mais de sobrevida das coroas MC já pode ser considerada um sucesso (Tabela 15). Entretanto, cabe a

TABELA 14- Para cimentação das coroas metalo-cerâmicas, qual o cimento que você utiliza?

\begin{tabular}{|c|c|c|c|c|}
\hline & Aracaju & Profissionais/Bauru & Estudantes/Bauru & Total \\
\hline Resinoso & $4 \%$ & $2,99 \%$ & $10,20 \%$ & $5,42 \%$ \\
\hline Resinoso dupla polimerização & $58 \%$ & $14,92 \%$ & $6,12 \%$ & $25,30 \%$ \\
\hline lonômero de vidro & $2 \%$ & $20,90 \%$ & $18,37 \%$ & $14,46 \%$ \\
\hline Fosfato de zinco & $36 \%$ & $59,70 \%$ & $65,31 \%$ & $54,22 \%$ \\
\hline Outros & $0 \%$ & $1,49 \%$ & $0 \%$ & $0,60 \%$ \\
\hline Total & $100 \%$ & $100 \%$ & $100 \%$ & $100 \%$ \\
\hline
\end{tabular}

TABELA 15- Nos últimos 8 anos, em seu consultório, qual foi o índice de sucesso no uso de suas coroas metalo-cerâmicas?

\begin{tabular}{|c|c|c|c|c|}
\hline & Aracaju & Profissionais/Bauru & Estudantes/Bauru & Total \\
\hline$=50 \%$ & $6 \%$ & $0 \%$ & $2,04 \%$ & $2,41 \%$ \\
\hline $60-70 \%$ & $10 \%$ & $4,48 \%$ & $6,12 \%$ & $6,63 \%$ \\
\hline$=80 \%$ & $36 \%$ & $35,82 \%$ & $28,57 \%$ & $33,73 \%$ \\
\hline$=90 \%$ & $36 \%$ & $52,24 \%$ & $38,78 \%$ & $43,37 \%$ \\
\hline Não responderam & $12 \%$ & $7,46 \%$ & $24,49 \%$ & $13,86 \%$ \\
\hline Total & $100 \%$ & $100 \%$ & $100 \%$ & $100 \%$ \\
\hline
\end{tabular}


ressalva quanto aos critérios adotados para considerar o sucesso de uma restauração. Na clínica odontológica, muitas vezes, o sucesso é avaliado pelo tempo em que a restauração permanece em posição, entretanto, se, ao remover uma coroa, verifica-se a presença de cárie que compromete seriamente o prognóstico do pilar, não se poderia considerar que essa coroa falhou muito tempo antes? Quando o processo de cárie teve início? Para que o sucesso de uma restauração possa ser avaliado não bastam critérios clínicos e sim, métodos de avaliação bem controlados e critérios bem estabelecidos.

Embora a cimentação provisória da prótese definitiva seja realizada por $63,25 \%$ dos entrevistados, esse número se deve ao fato de que $75,51 \%$ dos estudantes de Bauru realizam essa prática (Tabela 16). A Faculdade de Odontologia de Bauru indica a cimentação provisória das próteses definitivas ${ }^{17}$ como forma de proporcionar acomodação do ligamento periodontal, avaliação dos tecidos periodontais, oclusal, estética e funcional da prótese, possibilitando a execução de eventuais ajustes. Já Martignoni ${ }^{14}$ contra-indica a cimentação provisória por entender que não se obtém a mesma espessura de película com os cimentos provisórios, aumentando o risco de contatos prematuros ou interferências nas próteses definitivas, além de aumentar o risco de cárie devido à maior solubilidade dos cimentos provisórios. Entretanto, sabe-se há cimentos temporários capazes de fornecer película de cimentação compatível com os cimentos definitivos e que, para que ocorra cárie nessa fase, seria necessário que o paciente não estivesse com o processo de cárie controlado. A cárie depende da presença de patógenos e de dieta cariogência, os quais já deveriam ter sido eliminados ou controlados em fases anteriores do tratamento.

Um número significativo (42\%) dos dentistas de Aracaju respondeu que jamais utiliza esse tipo de proteção oclusal (Tabela 17). Conti ${ }^{3}$, em 1998 afirmou que o controle pós- reabilitação dos pacientes com desgaste dentário acentuado deve estar voltado para a manutenção e proteção das peças protéticas contra possíveis fraturas. Um meio adequado e indicado é a utilização das placas oclusais lisas. A utilização de oclusais metálicas em pacientes com bruxismo protegeria não apenas as peças protéticas de fraturas, como também a dentição antagonista de desgaste acentuado devido à diferença de dureza entre o esmalte dentário e a cerâmica. Apesar de existirem porcelanas que, ao serem glazeadas adquirem resistência ao desgaste similar à do esmalte dentário e que, por essa razão não causam desgaste excessivo da dentição antagonista, se o paciente apresentar hábitos parafuncionais, na ausência da placa oclusal, a cerâmica pode vir a sofrer esforços em demasia, podendo fraturar.

$\mathrm{Na}$ opinião dos entrevistados, 46,39\% afirmam que o desajuste cervical é a razão do fracasso das coroas MC. Para 27\% dos dentistas, a cárie é a razão do fracasso (Tabela 18). É difícil comparar tais resultados com os relatados na literatura devido aos diferentes modelos de estudo utilizados para avaliar a real influência desses aspectos sobre o sucesso das próteses. Por exemplo, o tratamento protético pode ter sido feito por clínicos gerais, por estudantes de graduação, ou dentro de clínicas especializadas e por numerosos clínicos ou por um só operador. Além disso, o próprio conceito de sucesso ou insucesso das próteses é variável. O desajuste cervical, pode ser devido a desajuste da própria infraestrutura, assim, as mesmas não deveriam sequer ter sido cimentadas, exigindo dos clínicos maior critério no momento da avaliação da adaptação marginal das mesmas. Sabe-se que muitas vezes, para que ocorra o assentamento correto de uma infra-estrutura a mesma precisa ser seccionada e unida para solda ${ }^{17}$, o fato de os profissionais de Aracaju realizarem com menor freqüência esse procedimento pode contribuir, em parte para o mais alto índice de pessoas que responderam desajuste cervical como razão de fracasso (Tabela 8). Outro fator que afeta a adaptação marginal é a

TABELA 16- Você realiza cimentação provisória de sua prótese "definitiva"?

\begin{tabular}{lcccc}
\hline & Aracaju & Profissionais/Bauru & Estudantes/Bauru & Total \\
\hline Sim & $58 \%$ & $58,21 \%$ & $75,51 \%$ & $63,25 \%$ \\
Não & $42 \%$ & $41,79 \%$ & $24,49 \%$ & $36,75 \%$ \\
Total & $100 \%$ & $100 \%$ & $100 \%$ & $100 \%$ \\
\hline
\end{tabular}

TABELA 17- O que você acha de superfícies oclusais em porcelana para pacientes que "rangem" os dentes?

\begin{tabular}{lllll}
\hline & Aracaju & Profissionais/Bauru & Estudantes/Bauru & Total \\
\hline Não há problema & $4 \%$ & $4,48 \%$ & $2,04 \%$ & $3,61 \%$ \\
Jamais usa & $42 \%$ & $22,39 \%$ & $10,20 \%$ & $24,70 \%$ \\
Usa, mas protege os dentes & $50 \%$ & $73,13 \%$ & $87,76 \%$ & $70,49 \%$ \\
Não responderam & $4 \%$ & $0 \%$ & $0 \%$ & $1,21 \%$ \\
Total & $100 \%$ & $100 \%$ & $100 \%$ & $100 \%$ \\
\hline
\end{tabular}


cimentação e o fato de os profissionais de Aracaju utilizaram com maior freqüência o cimento resinoso (que propicia linhas de cimentação mais espessas ${ }^{20}$ (Tabela 14)..

Em média, as próteses MC permanecem entre 6 e 10 anos na boca dos pacientes para 40,36\% dos entrevistados (Tabela 19). Esses dados estão de acordo a literatura e refletem um comportamento universal para a média dos pacientes. $^{21,25}$

A maioria dos entrevistados $(34,94 \%)$ manifestou o desejo de que as coroas em porcelana apresentassem maior facilidade de reparo das coroas em porcelana, diferente dos resultados de Christensen ${ }^{2}$, em que $41 \%$ dos entrevistados preferiram menor desgaste nos dentes antagonistas (Tabela 20).

Hoje, no mercado odontológico brasileiro, a existência das resinas compostas acompanhadas de agentes capazes de preparar a porcelana e torná-la receptiva aos processos de adesão. Sabe-se que esse tipo de reparo não confere à restauração suas características de resistência e estéticas originais carecendo, portanto, tais recursos de reparo, de aprimoramento nesse sentido.

Quanto ao desgaste nos dentes oponentes, já existe uma grande preocupação, por parte dos fabricantes em produzir materiais de dureza similar a do esmalte dentário. ${ }^{7}$ A Ivoclar, por exemplo, desenvolveu o IPS Empress 2, cujo mineral empregado para o material de recobrimento é a fluorapatita, com transparência, fluorescência, opalescência, grau e capacidade de abrasão praticamente iguais aos apresentados pelo esmalte dental. Entretanto, mais estudos clínicos controlados são necessários para confirmar suas propriedades.

\section{RESUMO E CONCLUSÕES}

Com enfoque em diversos aspectos da utilização clínica das restaurações MC na prática odontológica diária, chegouse às seguintes conclusões: 1) As coroas de MC são as restaurações protéticas dentais mais utilizadas. 2) A maior parte dos dentistas considera as coroas MC restaurações bem sucedidas, indicando superfícies oclusais em porcelana para a maioria dos pacientes. 3) Apesar de a esmagadora maioria utilizar as ligas de $\mathrm{Ni}-\mathrm{Cr}$ nas coroas $\mathrm{MC}$ em seus pacientes, os mesmos prefeririam a utilização de ligas nobres e seminobres nas restaurações realizadas em seus próprios dentes. 4) A maioria dos entrevistados utiliza coroas MC para o restabelecimento dos dentes anteriores (57,23\%). 5) Com relação à cimentação, a maioria utiliza o fosfato de zinco na cimentação das coroas MC e elege a porcelana Vita $(34,34 \%)$ para a confecção das restaurações, enquanto $13,86 \%$ escolhe a Noritake e Dulceram Plus. 6) A melhoria mais reivindicada para as coroas MC foi maior facilidade de reparo.

TABELA 18- Em sua opinião, qual seria a razão do fracasso das coroas metalo-cerâmicas?

\begin{tabular}{lllll}
\hline & Aracaju & Profissionais/Bauru & Estudantes/Bauru & Total \\
\hline cáries & $14 \%$ & $29,85 \%$ & $36,74 \%$ & $27,11 \%$ \\
cimentação & $0 \%$ & $0 \%$ & $4,08 \%$ & $1,21 \%$ \\
Desajuste cervical & $60 \%$ & $38,81 \%$ & $42,86 \%$ & $46,39 \%$ \\
Doença periodontal & $8 \%$ & $10,45 \%$ & $4,08 \%$ & $7,83 \%$ \\
Perda de faceta & $14 \%$ & $2,98 \%$ & $0 \%$ & $5,42 \%$ \\
Outras razões & $4 \%$ & $16,42 \%$ & $10,20 \%$ & $10,84 \%$ \\
Não responderam & $0 \%$ & $1,49 \%$ & $2,04 \%$ & $1,21 \%$ \\
Total & $100 \%$ & $100 \%$ & $100 \%$ & $100 \%$ \\
\hline
\end{tabular}

TABELA 19- Quanto tempo, em média, suas próteses metalo-cerâmicas permanecem na boca de seus pacientes?

\begin{tabular}{lllll}
\hline & Aracaju & Profissionais/Bauru & Estudantes/Bauru & Total \\
\hline Menos de 1 ano & $0 \%$ & $0 \%$ & $0 \%$ & $0 \%$ \\
Entre 1 e 3 anos & $0 \%$ & $0 \%$ & $0 \%$ & $0 \%$ \\
Entre 3 e 6 anos & $18 \%$ & $2,96 \%$ & $16,33 \%$ & $11,45 \%$ \\
Entre 6 e 10 anos & $46 \%$ & $38,82 \%$ & $36,73 \%$ & $40,36 \%$ \\
Mais de 10 anos & $22 \%$ & $38,82 \%$ & $12,25 \%$ & $25,90 \%$ \\
Não responderam & $14 \%$ & $19,40 \%$ & $34,69 \%$ & $22,29 \%$ \\
Total & $100 \%$ & $100 \%$ & $100 \%$ & $100 \%$ \\
\hline
\end{tabular}


TABELA 20- Atualmente, o que você gostaria que melhorasse nas qualidades de coroas em porcelana?

\begin{tabular}{|c|c|c|c|c|}
\hline & Aracaju & Profissionais/Bauru & Estudantes/Bauru & Total \\
\hline \multicolumn{5}{|l|}{ Menos desgaste nos } \\
\hline dentes oponentes & $20 \%$ & $20,90 \%$ & $22,45 \%$ & $21,08 \%$ \\
\hline Custo menor de laboratório & $12 \%$ & $20,90 \%$ & $18,37 \%$ & $17,47 \%$ \\
\hline Maior facilidade de confecção & $10 \%$ & $10,45 \%$ & $4,08 \%$ & $8,44 \%$ \\
\hline Melhor resistência & $4 \%$ & $7,46 \%$ & $8,16 \%$ & $6,63 \%$ \\
\hline Maior facilidade de reparo & $52 \%$ & $28,35 \%$ & $26,53 \%$ & $34,94 \%$ \\
\hline outros & $2 \%$ & $10,45 \%$ & $20,41 \%$ & $10,84 \%$ \\
\hline Não responderam & $0 \%$ & $1,49 \%$ & $0 \%$ & $0,6 \%$ \\
\hline Total & $100 \%$ & $100 \%$ & $100 \%$ & $100 \%$ \\
\hline
\end{tabular}

\section{ABSTRACT}

The current features of ceramic fused to metal crowns were evaluated by means of a questionnaire composed by 20 questions concerning the use of this type of restoration in the daily dental practice of professionals from Aracaju, Bauru and post-graduation students in the area of dental prosthesis. The conclusions were as follows: 1. Ceramic fused to metal crowns are the most employed restorations in Dentistry. 2. Most dentists regard ceramic fused to metal crowns as successful restorations, indicating ceramic occlusal surfaces for most of the patients. 3. Even though most professionals use nickel-chromium alloys in ceramic fused to metal crowns for their patients, they prefer the use of noble and semi-noble alloys for restorations in their own mouths. 4. The majority of the interviewees employ ceramic fused to metal crowns for rehabilitation of anterior teeth $(57.23 \%)$. Nevertheless, this was due to the fact that $78 \%$ of the dentists from Aracaju preferred this type of restoration, whereas in Bauru most professionals and students make use of ceramic crowns. 5. Most professionals apply zinc phosphate cement for the placement of ceramic fused to metal crowns. Most of them prefer to use Vita porcelain (34.34\%), compared to $13.86 \%$ for the Noritake and Dulceram Plus porcelains. 6 . The most desired improvement for ceramic fused to metal crowns was the possibility of easy repair.

UNITERMS: Questionnaires; Fixed partial denture; Ceramics.

\section{REFERÊNCIAS BIBLIOGRÁFICAS}

1- Blair FM, Wassell RW, Steele JG. Crowns and other extracoronal restorations: preparations for the full venner crowns. Brit Dent J 2002; 192(10): 561-71.

2- Christensen GJ. The use of porcelain-fused-to-metal restorations in current dental practice: a survey. J Prosthet Dent 1986; 56(1):13.
3- Conti PCR. Patologias oclusais e disfunções craniomandibulares. In Pegoraro, LF et al. editores. Prótese Fixa. São Paulo: Artes Médicas, 1998. p.23-40.

4- Dahl BL, Carlsson GE, Ekfeldt A. Occlusal wear of teeth and restorative materials. Acta Odontol. Scand 1993; 51:299-311.

5- Fischer J. Esthetics and prosthetics: an interdisciplinary consideration of the state of the art. Chicago: Quintessence, Co, 1999.

6- IBGE - Instituto Brasileiro de Geografia e Estatística. 2003 Junho. Disponível na: URL: http://www.ibge.gov.br.

7- Jones DW. Desenvolvimento da cerâmica odontológica. In.: Cerâmicas, clínica odontológica da América do Norte.

São Paulo: Roca; 1988.

8- Karlsson S. A clinical evaluation of fixed bridges, 10 years following insertion. J Oral Reabil 1986;13(5): 423-32.

9- Karlsson S. Failures and length of service in fixed prosthodontics after long-term function: a longitudinal clinical study. Swed Dent J 1989; 13(5): 185-92.

10- Land CM. A new system of restoring badly decked teeth by means of an enameled mettalic cooting. apud Shillingburg HT, et al. Atlas de talhados para coronas. Berlim: Quintessence, 1976, p. 125

11- Leinfelder KF, Lemons JE. Clínica restauradora: materiais e técnicas. São Paulo: Artes Médicas; 1990. p.323-9.

12- Lindhe J. Tratado de periodontologia clínica. Rio de Janeiro: Guanabara Koogan, 1992.

13- Magne P, Oh WS, Pintado MR, DeLong R. Wear of enamel and vennerign ceramics after laboratory and chairside finishing procedures. J Prosthet Dent 1999; 82(6): 669-79.

14- Martignoni M, Schönenberger A, editors. Cementation and final precision of the restoration. In: Precision fixed prosthodontics: cinical and laboratory aspects. Chicago: Quintessece Co.; 1993. 
15- McLaren EA. All ceramic alternatives to convencional metal ceramic restorations. Comp. Contin. Educ 1998; 19(3): 307-25.

16- McLean JW. The science and art of dental ceramic. Chicago: Quintessence Publ Co; 1979.

17- Pegoraro LF, Valle AL do, Araújo C dos R P de, Bonfante G, Conti PCR, Bonachela, WC. Prótese Fixa. São Paulo: Artes Médicas; 1998.

18- Phillips RW. Skinner - materiais dentários. São Paulo: Guanabara Koogan; $1993^{(\mathrm{C})}$.

19- Preston J. Fouth simposyum on dental ceramics, Chicago: Quintessence Co., 1988.

20- Rosenstiel SF, Land MF, Crispin BJ. Dental luting agents: a review of the current literature. J Prosthet Dent 1998; 80(3): 280301

21-Schwartz NL, Whitsett LD, Berry TG, Stewart JL Unserviceable crowns and fixed partial dentures: life-span and causes for loss of serviceability. J. Amer. dent. Ass 1970; 81(6): 1395-401.

22-Seymour KG, Samarawichrama DYD, Lynch EJ. Metal ceramic crowns - a review of tooth preparation. Eur J Prosthodont Rest Dent 1999 7(2): 79-84

23- Silva AM. Avaliação da alteração dimensional de modelos de gesso obtidos através de diferentes técnicas de transferência dos casquetes de moldagem. [tese]. Bauru (SP): Faculdade de Odontologia de Bauru, Universidade de São Paulo, 1999.

24-Valderhaug J. 15-year clinical evaluation of fixed prosthodontics. Acta Odontol Scand. 1991; 49(1):35-40.

25- Walton JN, Gardner MF; Agar JR. A survey of crown and fixed partial denture failures: length of service and reasons for replacement. J Prosthet Dent. 1986; 56(4):416-21.

Recebido para publicação em: 19/12/2002

Enviado para reformulações em: 09/06/2003

Pronto para publicação em: 01/10/2003

Endereço para envio de correspondência:

Paulo César Rodrigues Conti

Alameda Dr. Octávio Pinheiro Brisolla, 9-75, CXP 73

CEP 17012-901

Fone: (14) 2358277

Fax: (14) 2358277

e-mail: pcconti@pcab.com.br

Bauru - SP 